\title{
Lithium Air Battery: Alternate Energy Resource for the Future
}

\author{
Awan Zahoor ${ }^{\mathrm{a}}$, Maria Christy ${ }^{\mathrm{b}}$, Yun Ju Hwang ${ }^{\mathrm{b}}$, and Kee Suk Nahm ${ }^{\mathrm{a}, \mathrm{b}, \uparrow}$ \\ ${ }^{a}$ Department of Semiconductor and Chemical Engineering, Chonbuk National University, Jeonju 561-756, \\ Republic of Korea \\ ${ }^{b} R \& D$ Education Center for Fuel Cell Materials \& Systems, Chonbuk National University, Jeonju 561-756, \\ Republic of Korea
}

\begin{abstract}
:
Increasing demand of energy, the depletion of fossil fuel reserves, energy security and the climate change have forced us to look upon alternate energy resources. For today's electric vehicles that run on lithium-ion batteries, one of the biggest downsides is the limited range between recharging. Over the past several years, researchers have been working on lithium-air battery. These batteries could significantly increase the range of electric vehicles due to their high energy density, which could theoretically be equal to the energy density of gasoline. Li-air batteries are potentially viable ultrahigh energy density chemical power sources, which could potentially offer specific energies up to $3000 \mathrm{Whkg}^{-1}$ being rechargeable. This paper provides a review on Lithium air battery as alternate energy resource for the future.
\end{abstract}

Keywords: Porous air cathode, Catalyst, Lithium air battery, Electrolyte, Energy storage

Received March 3, 2012 : Accepted March 27, 2012

\section{Introduction}

Depletion of global fossil oil resources has been the theme topic of the world economic and political circles over the past decades. How the alternatives can be exploitable, while being economically cost-effective, are the key factors in coming up with conclusions and making decision on the part of consumers. Over the past several decades, the consumer countries have been weighing up the use of other resources, or substitutes, such as solar, water, wind, nuclear etc. Although huge research works have been done, it sounds a serious step has not been taken yet; mainly because there have been gigantic amount of this noble energy carrier, namely the oil, comparing with other substitute resources being highly cost effective. So all this have made weak incentives for the use of other resources. But over the past several years, researchers have been

${ }^{\dagger}$ Corresponding author. Tel.: +82-63-270-2311

E-mail address: nahmks@jbnu.ac.kr working on an alternative battery called a lithium-air battery which gives the energy density almost equivalent to the gasoline. By the use of this battery in electric vehicles just by changing the electrode in the lithium ion to air, it would be possible for a battery of the same size and weight to hold up to 10 times more energy-potentially harnessing the same energy density as petrol. Such lithium-air batteries have an anode made of lithium which is oxidized by the oxygen cathode (drawn from environment air), releasing energy. Pumping electricity into the battery reverses the procedure, pushing out the oxygen and leaving the lithium. In 1996, Abraham and Jiang ${ }^{1)}$ proposed the lithium air battery composed of non-aqueous polymer electrolyte. Several research groups followed up this work coming up with different Lithium air battery systems. ${ }^{2)}$ This battery comprises of lithium metal anode which plays a role as a lithium source in lithium air battery and carbon based air cathode and catalyst. The operation of this battery is almost similar to the hydrogen fuel cell in which hydrogen ions moves through elec- 
trolyte to meet with oxygen at cathode and forms water as a product which is not stored in the cell but in lithium air battery lithium ions moves through electrolyte and meet with oxygen at air cathode which is normally obtained from air and forms Lithium oxide which is accumulated inside the porous electrode. The major difference between the two is that for lithium air battery an open system is required for the oxygen and as well as dehydration membrane ${ }^{3,4)}$ because lithium metal is very sensitive to moisture and aggressively reacts with water.

\section{Working Principle and the Electrochem- ical Reactions of Lithium Air Batteries}

As we know during discharge, lithium ions dissolve from the surface of the lithium metal anode and transfer to the cathode through the electrolyte and during charge, the lithium ions transfer back to the anode to be back onto the surface of the lithium metal (Fig.1).

Lithium air batteries based on the electrolyte used can be classified into four types: (Fig. 2)

(i) Non-aqueous electrolytes

(ii) Aqueous electrolytes

(iii) Hybrid electrolytes (Combination of (i) \& (ii) or (iv))

(iv) Solid state electrolytes

i.e. fully aprotic or non-aqueous, ${ }^{5-10)}$ aqueous ${ }^{10-16)}$ mixture of aprotic and aqueous liquid electrolytes system and fully solid cell with solid electrolyte system. ${ }^{15,17)}$

Based on non-aqueous electrolyte solvent Abraham

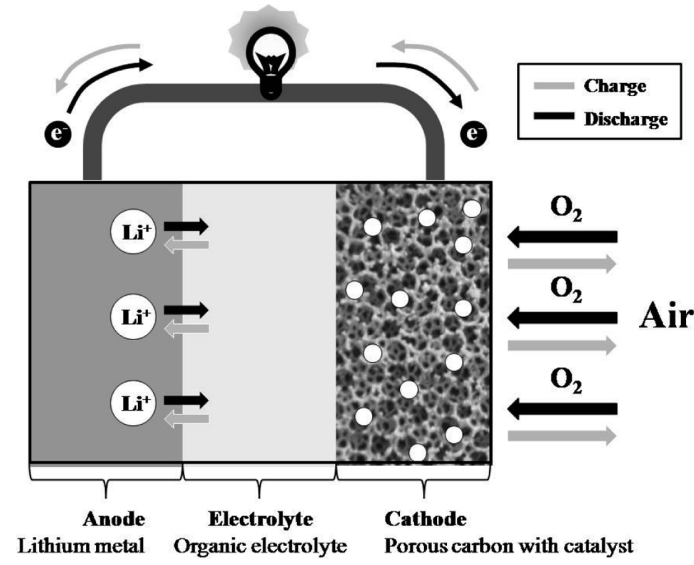

Fig.1. Working Principle of the lithium batteries. et al. ${ }^{1)}$ was the first to suggest the following reaction mechanism:

$$
\begin{aligned}
& \mathrm{Li}+\frac{1}{2} \mathrm{O}_{2} \rightarrow \frac{1}{2} \mathrm{Li}_{2} \mathrm{O}_{2} \\
& \mathrm{Li}+\frac{1}{4} \mathrm{O}_{2} \rightarrow \frac{1}{2} \mathrm{Li}_{2} \mathrm{O}
\end{aligned}
$$

The reversible cell voltage is $E^{\mathrm{o}}=3.10 \mathrm{~V}$ for the reaction (1) and $E^{\circ}=2.91 \mathrm{~V}$ for reaction (2). The standard cell potentials were calculated by using the standard Gibbs free energy of formation. Lu et al. ${ }^{18)}$ reported the reversible cell voltages according to the following equations:

$$
\begin{aligned}
& 2 \mathrm{Li}+\mathrm{O}_{2} \rightarrow \mathrm{Li}_{2} \mathrm{O}_{2} \\
& 4 \mathrm{Li}+\mathrm{O}_{2} \rightarrow 2 \mathrm{Li}_{2} \mathrm{O}
\end{aligned}
$$

The reversible cell voltage in this case is $E^{\mathrm{o}}=2.96 \mathrm{~V}$ for the reaction (3) and $E^{\mathrm{o}}=2.91 \mathrm{~V}$ for reaction (4), and $\mathrm{E}$ is referred as $\mathrm{Li} / \mathrm{Li}^{+}$.

$E^{\mathrm{o}}=-\Delta G / n F$, where $\Delta G=$ Gibbs free energy of the reaction, $\mathrm{n}=$ number of electrons transferred and $\mathrm{F}=$ Faraday constant.

Furthermore Read et al. ${ }^{19)}$ and Ogasawara et al. ${ }^{20)}$ have introduced almost same type of reactions which are based on non-aqueous electrolytes, where each group have proposed some benefits and challenges of using aprotic electrolyte.

Aqueous and hybrid versions of electrolytes are also investigated by other groups to study their reaction mechanism. Polyplus ${ }^{21)}$ developed the aqueous electrolyte version and Polyplus and Wang et al. ${ }^{22)}$ devel-

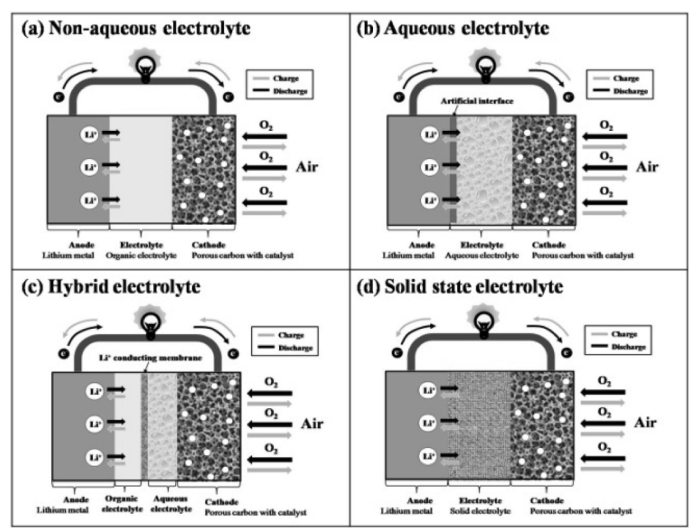

Fig. 2. Lithium air batteries based on the electrolyte used in the battery. 
oped hybrid electrolyte version. The hybrid electrolyte version consists of lithium metal anode, non aqueous electrolyte, super ionic conducting glass ceramic membrane, aqueous electrolyte and the air cathode. The fundamental reaction mechanism for both aqueous and hybrid electrolytes are similar. The fundamental reaction mechanisms for the aqueous electrolytes are as follows,

$$
2 \mathrm{Li}+\frac{1}{2} \mathrm{O}_{2}+2 \mathrm{H}^{+} \rightarrow 2 \mathrm{Li}^{+}+\mathrm{H}_{2} \mathrm{O}
$$

(in acidic electrolyte)

$$
2 \mathrm{Li}+\frac{1}{2} \mathrm{O}_{2}+\mathrm{H}_{2} \mathrm{O} \rightarrow 2 \mathrm{LiOH}
$$

(in alkaline electrolyte)

The main advantage of the aqueous electrolyte is that the discharge product is easily soluble in $\mathrm{H}_{2} \mathrm{O}$ which prevents the cathode to be choked by discharge product so that the oxygen diffusion can be enhanced which leads to the improvement in better cycling efficiency. The main challenge for the aqueous and mixed electrolytes is to prevent the lithium metal to react with $\mathrm{H}_{2} \mathrm{O}$ because lithium reacts very aggressively with water. There is a need to develop a lithium ion conducting membrane which protect the lithium to react directly with water i.e. water stable artificial solid electrolyte interface is required which is well known SEI. In mixed and non-aqueous electrolyte

Table 1. Average lithium cycling efficiencies for $\mathrm{Li}$ deposited on nickel substrates at 25 and $50^{\circ} \mathrm{C}$ in $\mathrm{VC}$ added

\begin{tabular}{|c|c|c|c|c|}
\hline \multirow{2}{*}{ Li salts } & \multirow{2}{*}{ Solvent } & \multirow{2}{*}{$\begin{array}{l}\text { Temp. } \\
\left({ }^{\circ} \mathrm{C}\right)\end{array}$} & \multicolumn{2}{|c|}{$\begin{array}{l}\text { Lithium cycling } \\
\text { efficiency }\end{array}$} \\
\hline & & & VC free & $\begin{array}{c}\text { With VC } \\
2 \%\end{array}$ \\
\hline \multirow{3}{*}{$\mathrm{LiPF}_{6}$} & $\mathrm{EC}+\mathrm{DMC}(1: 1)$ & 0 & 60 & 57 \\
\hline & $\mathrm{EC}+\mathrm{DMC}(1: 1)$ & 25 & 64 & 80 \\
\hline & $\mathrm{EC}+\mathrm{DMC}(1: 1)$ & 50 & 53 & 95 \\
\hline \multirow{3}{*}{$\mathrm{LiBF}_{4}$} & $\mathrm{EC}+\mathrm{DMC}(1: 1)$ & 0 & 82 & 55 \\
\hline & $\mathrm{EC}+\mathrm{DMC}(1: 1)$ & 25 & 62 & 80 \\
\hline & $\mathrm{EC}+\mathrm{DMC}(1: 1)$ & 50 & 40 & 84 \\
\hline \multirow{3}{*}{ LiTFSI } & $\mathrm{EC}+\mathrm{DMC}(1: 1)$ & 0 & 77 & 54 \\
\hline & $\mathrm{EC}+\mathrm{DMC}(1: 1)$ & 25 & 68 & 82 \\
\hline & $\mathrm{EC}+\mathrm{DMC}(1: 1)$ & 50 & 72 & 91 \\
\hline \multirow{3}{*}{ LiBETI } & $\mathrm{EC}+\mathrm{DMC}(1: 1)$ & 0 & 73 & 58 \\
\hline & $\mathrm{EC}+\mathrm{DMC}(1: 1)$ & 25 & 72 & 86 \\
\hline & EC+DMC(1:1) & 50 & 66 & 90 \\
\hline
\end{tabular}
electrolyte using pressurized electrode cell systems natural SEI is developed because the electrolytes are in direct contact with the lithium metal anode.

A fully solid-state Li-air battery was recently reported by Kumar et al. ${ }^{23)}$ The battery chemistry has been studied by various groups ${ }^{24,25)}$ and is still being studied by various research groups.

All the four battery systems have their own merits and demerits which should be overcome to push the $\mathrm{Li}$ air batteries into practical applications. Various other electrolytes are discussed in detail in the following sections.

\section{Lithium Air Anode Characteristics}

Lithium is the lightest of all metals and has the greatest electrochemical potential and high reversible capacity $3,860 \mathrm{mAh} / \mathrm{g}$. During discharge, lithium ions dissolve from the surface of the lithium metal anode and transfer to the cathode through the electrolyte and during charge, the lithium ions transfer back to the anode to be back onto the surface of the lithium metal anode. The inherent problem with the lithium metal anode is the dendrite formation which occurs during charging when the lithium metal reacts with the organic electrolyte forming a passive layer on their surface resulting in the non-uniform plating of lithium. This also leads to short circuit between anode and cathode and to serious safety problems due to localized hot spots. For the high energy density, higher cycling efficiency and the safety of lithium air batteries, it is most important to control the lithium metal anode and electrolyte interface. Till date researchers are trying to find out the best solution for the stability of lithium metal anode which includes gel electrolytes, ${ }^{26)}$ the protective layers coated on metallic lithium $^{27)}$ with layers that are composed of ceramic or glass which conduct the lithium ions etc. Also use of different electrolytes and/or additives ${ }^{28)}$ to modify the SEI and/or the morphology of deposited lithium.

The effect of protective layers on lithium metal anode has been investigated by many researchers and the morphology and composition of SEI has been observed. For example Arie et al. ${ }^{29)}$ investigated the effect of diamond like carbon coating on lithium metal anode by RF-PECVD (radio frequency plasma enhanced chemical vapor deposition), at elevated temperatures and $0.2 \mathrm{C}$ rate. The DLC coated lithium metal anode showed the most improved electrochemical properties with the highest specific capacity 

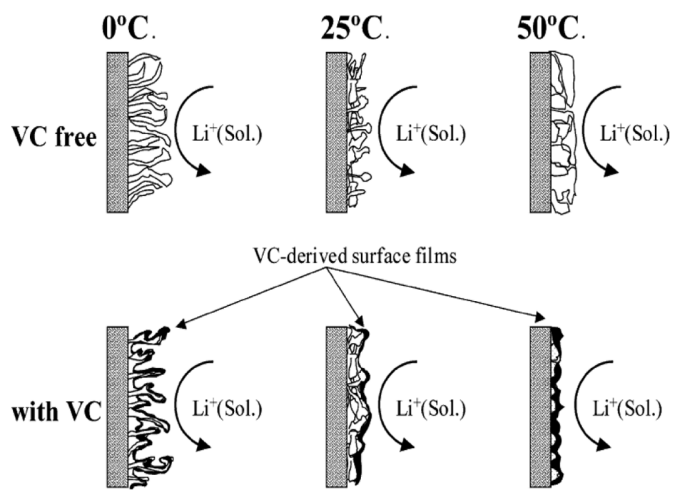

Fig. 3. Schematic illustrations for deposited lithium in $\mathrm{LiPF}_{6} / \mathrm{EC}+\mathrm{DMC}(1: 1)$ containing VC. $\left.{ }^{29}\right)$

$60 \mathrm{mAh} / \mathrm{g}$ after 50 cycles. This implies that the reversibility of the lithium electrode can be enhanced by the deposition of DLC film at higher substrate temperature because the relatively high $\mathrm{sp}^{3}$ carbon content helps in the transport of lithium ions. This coating develops a thin layer on the lithium metals which protects the lithium metal anode from direct contact of electrolyte and suppresses the formation of dendrites.

Visco et al. ${ }^{30)}$ used a thin ceramic film of LISICON which is highly super ionic lithium conductor on lithium metal anode. The main advantage of ceramic films is to create a barrier between lithium metal anode and the electrolyte and to protect the anode from atmospheric contaminations. Ishikawa et al. ${ }^{31)}$ investigated the effect of aluminum iodide $\left(\mathrm{AlI}_{3}\right)$ and magnesium iodide $\left(\mathrm{MgI}_{2}\right)$ as additives in the electrolytes on lithium batteries. It is reported that $\mathrm{Li}-\mathrm{Mg}$ and Li-Al alloy layers forms a thin film at the electrodeelectrolyte interface which suppresses the dendrite formation on lithium and ultimately increases the charge discharge cycles. In PC/DMC with $\mathrm{LiPF}_{6}$ the addition of magnesium iodide shows the improved Li cycling efficiency than the addition of aluminum iodide, because by the addition of $\mathrm{AlI}_{3}$ a decomposition product $\mathrm{PF}_{6}$ is formed at the interface which impedes the charge discharge cycling while on the other hand addition of $\mathrm{MgI}_{2}$ provides a low resistance interface to the lithium metal anode and facilitates the Li charge-discharge process. Low cycling efficiency has been reported ${ }^{32}$ with the addition of $\mathrm{AlI}_{3}$ in $\mathrm{LiPF}_{6}+\mathrm{PC}+\mathrm{DMC}$ due to the formation of phosphoric, fluorophosphoric acid type compounds and fluorocarbons by the decomposition of $\mathrm{LiPF}_{6}$ at the lithium anode interface. These compounds exhibit more resis- tance to the lithium ions which leads to the low cycling efficiency. Ota et al. ${ }^{28)}$ reported the positive effects of vinyl carbonate as an additive in various electrolytes and the increase in cycling efficiency of lithium anode at elevated temperatures. At $50^{\circ} \mathrm{C}$ there is no dendritic morphology observed in Fig. $3{ }^{28)} \mathrm{VC}$ derived surfaces at high temperature prevents any reaction between deposited lithium and the electrolyte and the thickness of the surface is thinner at $50^{\circ} \mathrm{C}$ with $\mathrm{VC}$ added electrolyte. It is also reported that the effect of stack pressure on the lithium anode depends upon the type of electrolytes. Table $1^{28)}$ shows the lithium cycling efficiencies at three different temperatures with different lithium salts dissolved in EC/DMC $(1: 1)$. At high temperatures the lithium ion conductivity of the VC containing electrolyte is increased due to the formation of thinner surface films on the lithium metal anode which facilitates the high migration of lithium ions through the electrolyte and suppresses the dendrite formation. It should be noted that the initial condition of the native surface film plays an important role in surface modification because of the lithium being covered with surface films which are called native films consisting of $\mathrm{Li}_{2} \mathrm{CO}_{3}, \mathrm{LiOH}$ and $\mathrm{Li}_{2} \mathrm{O}$. Therefore surface modification of lithium is necessary for the highly reversible lithium metal anode. Shiraishi et al. ${ }^{32)}$ reported that addition of small amount of HF in the electrolyte can change the surface morphology and SEI from $\mathrm{Li}_{2} \mathrm{CO}_{3} \mathrm{LiOH}$ and $\mathrm{Li}_{2} \mathrm{O}$ layer to $\mathrm{LiF} / \mathrm{Li}_{2} \mathrm{O}$ bilayer decreasing the thickness of the surface film. This bilayer can also protect the lithium metal and the dendrite formation and suppresses it for several discharge and charge cycles. It is also suggested that thin layer of LiF prevents the direct lithium metal electrolyte contact and inhibits the formation of dendritic lithium. ${ }^{32,33)}$

Higher coulombic efficiency of about $85 \%$ can be obtained by using (polyvinylidene fluoride hexa fluoropropylene) PVdF-HFP gel type electrolyte. ${ }^{34)}$ Uniform morphology and smaller interface resistance is observed because of the stability of PVdF-HFP gel electrolyte to the lithium metal anode than any other electrolyte. By addition of $\mathrm{CO}_{2}$ in PVdF-HFP gel electrolyte the coulombic efficiency of $95 \%$ was reported $^{34)}$ due to the decrease in the interface resistance caused by the addition of $\mathrm{CO}_{2}$. Increase in specific capacity was reported at low oxygen pressure by Zhang et al. ${ }^{35)}$ By using low volatile trifluoroethyle phosphate TFP based electrolytes, $83 \%$ coulombic 
efficiency was reported i.e. by using low volatility lithium air battery can be used in ambient environment. It should be noted that the improvement in specific capacity is attributed to the dissolution kinetics and increase of oxygen solubility in TFP based electrolytes. Less dendritic and smoother surface is reported ${ }^{36)}$ by using semi-interpenetrating polymer network (IPN) structure for the protection of lithium electrode formed by ultraviolet (UV) radiation-curing method. A curable mixed solution consists of linear polymer (Kynar 2801 dissolved in tetrahydrofuran), a crosslinking agent (1, 6-Hexanediol diacrylate), liquid electrolyte (ethylene carbonate $(\mathrm{EC}) /$ propylene carbonate $(\mathrm{PC}) / 1 \mathrm{M}$ $\mathrm{LiClO}_{4}$ ) and a photo initiator (methyl benzoylformate). It is suggested ${ }^{32)}$ that deposition of dendritic lithium can be suppressed by the introduction of the semi-IPN structure based protection. A protective layer based on IPN structure ${ }^{37)}$ was also formed on lithium electrode surface by coating a curable mixed solution on lithium metal surface followed by radiation with UV light for 2 minutes and recently the mechanism of lithium and lithium composite anodes ${ }^{38)}$ are reported by Liu et al.

\section{Lithium Air Cathode Characteristics}

Lithium air cathode is almost similar to that of a fuel cell cathode. Oxygen is supplied from the atmosphere to the air cathode and reacts with lithium ions to form $\mathrm{Li}_{2} \mathrm{O}_{2}$ and is accumulated inside the porous cathode. In practice lithium air cathode have some serious challenges because the pores of the air cathodes are blocked by the discharge products like lithium peroxide precipitates. Because of this block in the pores, the oxygen gas and the lithium ion delivery to the internal pore volume stop. There are three crucial factors such as pore size, pore volume and surface area which can affect the performance and discharge capacity of the lithium air cathode. Carbon loading is another factor where the increase of carbon loading decreases the capacity $^{39-42)}$. Highest gravimetric capacity of 5813 $\mathrm{mAh} / \mathrm{g}$ is reported at a current density of $0.1 \mathrm{~mA} / \mathrm{cm}^{2}$ and a carbon loading of $1.9 \mathrm{mg}$. Unfortunately the increase of carbon loading results in the decrease in capacity because of the block in the pores resulting in very few pores left for oxygen flow and intercalation. Recently it has been demonstrated that the nitrogen doping of the carbon materials have significantly improved the performance of the lithium oxygen bat- tery. ${ }^{35)}$ The increase in cell performance indicates that the charge transfer resistance has been suppressed by the nitrogen doping and the ORR oxygen reduction reaction is improved. Nitrogen doping increases the porosity of the carbon material and the higher porosity improves the higher diffusivity of oxygen in nitrogen doped carbon which in turn enhances the cell capacity. ${ }^{43}$ Generally it is assumed that the specific capacity is proportional to the surface area because, larger the surface area more the lithium oxides formed and many active sites will be available for the reaction. In contrary Yang et al. ${ }^{44)}$ reported that surface area is a critical factor in the performance of air cathode and the specific capacity is not proportional to the surface area. Higher discharge capacity of $2500 \mathrm{mAh} / \mathrm{g}$ is reported $^{44)}$ by using mesoporous mesocellular carbon foam which is about $40 \%$ more than other carbon materials at a current density of $0.1 \mathrm{~mA} / \mathrm{cm}^{2}$. Large pore volume and large mesoporous mesocellular carbon foam allows more lithium oxides deposit during discharge process.

Xiao et al. ${ }^{45)}$ investigated different types of carbon materials for the air cathodes. On the basis of different experimental results they reported that specific capacity is proportional to the mesopore volume of the carbon materials. Electrolyte filling is another important factor with air cathodes because in flooded electrodes oxygen gas cannot be easily diffused and mobility of oxygen gas is very low in liquid phase as compared to that of gaseous phase. Therefore if the electrode is flooded with electrolyte then it leads to the poor discharge capacity. At constant current density the increase in the thickness of the air electrode leads to the poor electrochemical performance. ${ }^{46)}$ The specific capacity is decreased because the product is deposited near the electrode/air interface and within the oxygen diffusion length. If the thickness of air electrode is increased than oxygen diffusion length, major portion of the pore volume will not be filled by the lithium oxide which again leads to the decrease in specific capacity.

Effect of oxygen pressure has also been observed by many researchers. ${ }^{47-49)}$ All agrees that at high oxygen pressure the discharge capacity is increased. At low oxygen pressure the discharge product film is formed on air side of the electrode which ultimately stops the reaction between lithium ions and the oxygen where as high oxygen pressure of about $10 \mathrm{~atm}$ is helpful in preventing this film formation. ${ }^{48)}$ Read at al. ${ }^{47)}$ has con- 
cluded that the discharge capacity is proportional to the oxygen partial pressure and by using a semi-infinite medium model with simultaneous diffusion and reaction discharge capacity can be increased. The above mentioned fact shows that lithium air batteries can be useful only when the partial pressure of oxygen is higher than atmospheric pressure of oxygen which is about $0.2 \mathrm{~atm}$. It is also suggested that the discharge capacity can be increased by decreasing the electrolyte viscosity.

\section{Electrolytes for the Lithium Air Batteries}

Effect of non-aqueous electrolytes has been investigated on the performance of lithium/air batteries by $\mathrm{Xu}$ et al. ${ }^{50)}$ and Zhang et al. ${ }^{35)}$ Electrolytes with high polarity have ability to generate more tri-phase regions which leads to higher discharge capacity. ${ }^{52)}$ It implies that contact angle formed between the electrolyte and the air electrode has vital role on the performance of lithium/air batteries because of the oxygen diffusion rate through the open channels which is significantly higher than that through the liquid electrolyte. Zhang et al. ${ }^{35)}$ has reported a non-aqueous electrolyte that supports long-term operation of the $\mathrm{Li}$ / air battery in dry ambient environments based on a non-hydrolytic $\mathrm{LiSO}_{3} \mathrm{CF}_{3}$ salt and a low volatility propylene carbonate (PC)/tris(2,2,2-trifluoroethyl) phosphate (TFP) solvent blend. They have also reported that it is possible to develop a non-aqueous electrolyte for the operation of $\mathrm{Li}$ /air batteries in dry ambient environments by selecting low volatile fluorinated compound as a co-solvent. ${ }^{51)}$

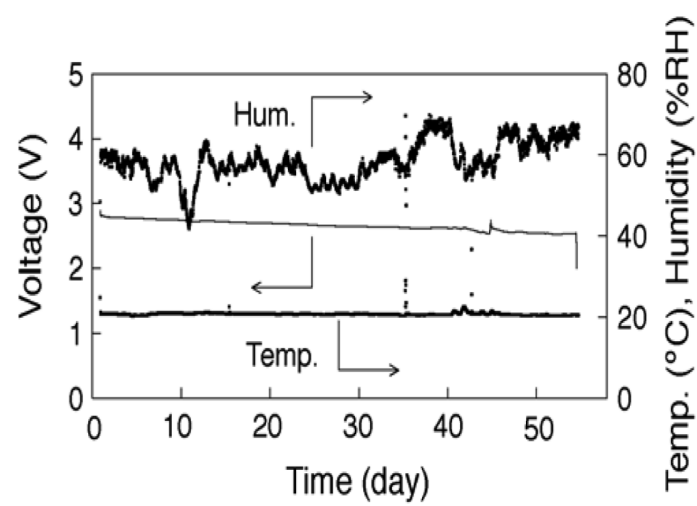

Fig. 4. The effect of humidity on discharge profile. Electrolyte: $0.5 \mathrm{M}$ LiTFSI-EMITFSI; I: $0.01 \mathrm{mAcm}-2$; in air. $^{54)}$
Although the use of partially fluorinated solvents reduces ionic conductivity of the liquid electrolyte, it really enhances discharge performance of $\mathrm{Li} /$ air cells, including both specific capacity and rate capability of the Li/air cells. Low volatility is another important factor on the performance of lithium air batteries, for the long term operation of lithium/air batteries in ambient environment electrolytes should be less volatile. Among various electrolytes, it is concluded that low volatile propylene carbonate (PC)/tris(2,2,2-trifluoroethyl) phosphate (TFP) is the best choice for the lithium air batteries. Increased dissolution kinetics and solubility of oxygen in TFP-containing electrolytes leads to the better performance of lithium/air battery. Laoire et al. ${ }^{8)}$ have shown the reversible reduction of $\mathrm{O}_{2}$ to long lived superoxide in $\mathrm{ai}^{+}$conducting electrolyte(LiPF $)_{6}$ in dimethyl sulfoxide(DMSO) for the first time which gives a rational approach for the selection of organic electrolyte solutions. The importance of establishing the 3-phase electrochemical interface in non-aqueous electrolyte is demonstrated by creating air-diffusion paths and an air saturated portion for an air cathode by Tran et al. ${ }^{49)}$ A near linear relationship between the capacity of gas diffusion electrode in a non-aqueous electrolyte and the average pore diameter was demonstrated, which could be used to estimate the capacity of the gas diffusion electrode quantitatively.

Charging process was also investigated by Xu et al. ${ }^{52}$ by using carbonate based electrolyte. It was reported that the discharged product was lithium alkyl carbonate and/or $\mathrm{Li}_{2} \mathrm{O}_{3}$ which shows that the discharge in a carbonate based electrolyte leads to the formation of carbonate species which causes the poor cycling efficiency of lithium air batteries. The result was confirmed by Xiao et al. ${ }^{53)}$ that discharge products from lithium oxygen batteries are $\mathrm{Li}_{2} \mathrm{CO}_{3}$ and $\mathrm{LiRCO}_{3}$ when using alkyl carbonate based electrolytes. It was reported that when discharged at $2.0 \mathrm{~V} \mathrm{Li}_{2} \mathrm{CO}_{3}$ is formed with $\mathrm{Li}_{2} \mathrm{O}_{2}$. It is generally assumed that the intermediate product of the reaction between $\mathrm{Li}$ and $\mathrm{O}_{2}$ is $\mathrm{LiO}_{2}$ which reacts with the carbonate solvent to form $\mathrm{Li}_{2} \mathrm{CO}_{3}$ while part of the intermediate $\mathrm{LiO}_{2}$ continues to be reduced to $\mathrm{Li}_{2} \mathrm{O}_{2}$ by accepting another electron and $\mathrm{Li}^{+}$ion. Kuboki et al. ${ }^{54)}$ reported that 1 alkyl-3-methyl imidazolium cation and Bis [(perfluoroalkyl)sulfonyl] imide anion gives the discharge capacity of $5360 \mathrm{mAh} / \mathrm{g}$. Fig. $4^{54)}$ shows the cell tested for 56 days in air and no significant effect of humidity 
and long discharge tests were observed on discharge behavior. Higher viscosity and conductivity of 1ethyl-3methyl imidazolium in (trifluoromethylsulfonyl) amide EMITFSI leads to the high discharge capacity of the cell, which shows that EMITFSI prevents the vaporization of the electrolyte and hydrolysis of the anode.

Solid electrolytes such as ceramic membrane ${ }^{55)}$ and polymer electrolytes are also under investigation by various research groups. Polymer electrolytes offer advantage over ceramic electrolytes with good processibility and flexibility. They also maintain dimensional stability, safety and the ability to prevent Lithium dendrite formation. ${ }^{56)}$ It is reported that polymer composite electrolyte membrane can effectively stabilize the interface and diminish lithium corrosion by water and thus deliver high discharge capacity with and without $\mathrm{O}_{2}$ catalyst. ${ }^{53)}$ Zhang et al. ${ }^{57)}$ investigated hydrophobic ionic liquid (1,2-dimethyl-3-propyl imidazolium) and bis(trifluoromethanesulfonyl) imide (PMMITFSI)) with silica-PVdF-HFP polymer composite. Zhang et al. has added liquid electrolyte into porous polymer film to get PVDF based porous gel polymer electrolyte $^{58)}$ and have observed very high Li ion conductivity. Hydrophobic property of the electrolyte makes it most suitable candidate for the lithium air batteries. Certain electrolytes are immiscible in water which makes it very beneficial for lithium air cell. It is suggested that hydrophobic ionic liquid electrolytes can be used to protect the lithium metal anode because chemical oxidation of lithium metal is likely to be occurred on the surface because of the moisture which can diffuse through the electrolyte. ${ }^{59)}$ Bonhote et al. suggested that ionic liquid 1-ethyl 3-methyl imidazolium in (trifluoro methyl sulfonyl) amide (EMITFSI) is immiscible in water and less conductive and its potential reactivity makes it useful ionic solvent. ${ }^{59)}$

\section{Effect of Catalysts}

Even though lithium air battery is a potentially transformational energy storage technology for transportation and stationary energy storage applications, its practical application is limited by various factors. Great challenges exist in air electrode and oxygen electro-catalysts. The electro catalysts for Oxygen reduction reaction play a key role in improving the power density, cyclability and energy efficiency of the battery. ${ }^{59-62)}$

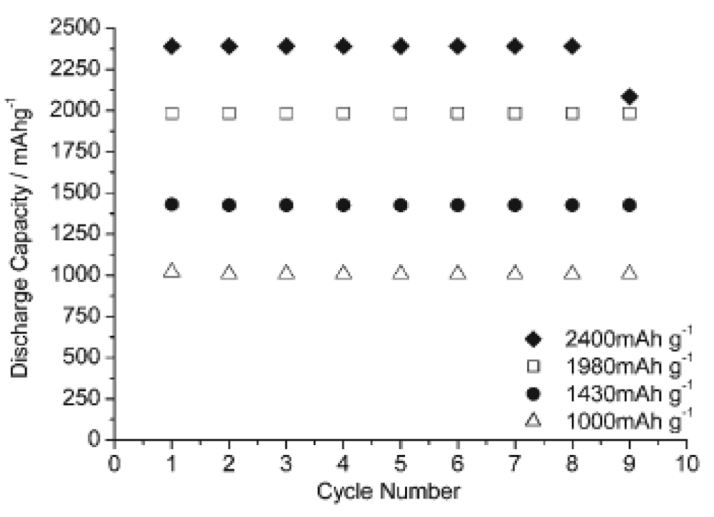

Fig. 5. Variation of discharge capacity with cycle number for porous electrodes containing a-MnO2 nanowires as catalyst when the state of discharge is limited to different degrees. Cycling rate of $70 \mathrm{mAg}^{-1}$. Capacities per gram of carbon in the electrode.

Various experimental results ${ }^{63,64)}$ show that $\mathrm{Pd} /$ $\mathrm{MnO}_{2}$ and $\alpha-\mathrm{MnO}_{2} / \mathrm{Pd}$ based catalysts might have some significant effect and increase the discharge capacity of the lithium air cell. It is reported ${ }^{63)}$ that with $\mathrm{Pd}$ mixed with $\mathrm{MnO}_{2}$ the charge potential can be reduced to $3.7 \mathrm{~V}$ and the energy efficiency is increased from 60 to $89 \%$. Charging potential can be further decreased to $3.6 \mathrm{~V}$ by the use of $\alpha-\mathrm{MnO}_{2} / \mathrm{Pd}$ catalyst. ${ }^{64)}$

The crystal structure of $\alpha-\mathrm{MnO}_{2}$ consists of $2 \times 2$ tunnels formed by edges and corner sharing $\mathrm{MnO}_{6}$ octahedral. $\mathrm{Li}_{2} \mathrm{O}$ can be incorporated within these tunnels with the $\mathrm{O}^{2-}$ ions at the center and lithium ions coordinated between these central $\mathrm{O}^{2-}$ ions and those forming the walls of the tunnel. The ability to accommodate both the $\mathrm{O}^{2-}$ and the $\mathrm{Li}^{+}$ions within the tunnels suggests the possibility of incorporation of $\mathrm{Li}^{+}$and $\mathrm{O}_{2}{ }^{2-}$ ions. Such incorporation is not possible in other manganese based oxides. The role of $\alpha-\mathrm{MnO}_{2}$ nanorods were investigated by Zhang et al. ${ }^{65)}$ It is reported that the discharge product $\mathrm{Li}_{2} \mathrm{O}$ reacts with $\alpha-\mathrm{MnO}_{2}$ to form $\mathrm{Li}_{2} \mathrm{MnO}_{3}$ during discharge and $\mathrm{Li}_{2} \mathrm{O}$ could be removed electrochemically from $\mathrm{LiMnO}_{3}$ which helps in the enhancement of the charging process of the electrode reaction. Oxygen reduction reaction has been significantly reduced to $2.1 \mathrm{~V}$ by the use of $\alpha$ $\mathrm{MnO}_{2}$ rods which is slightly less than other reported values.

Débart et al. ${ }^{66)}$ investigated the performance of various manganese oxide based catalysts on the discharge capacity of lithium air cells for example $\alpha-\mathrm{MnO}_{2}, \beta$ - 


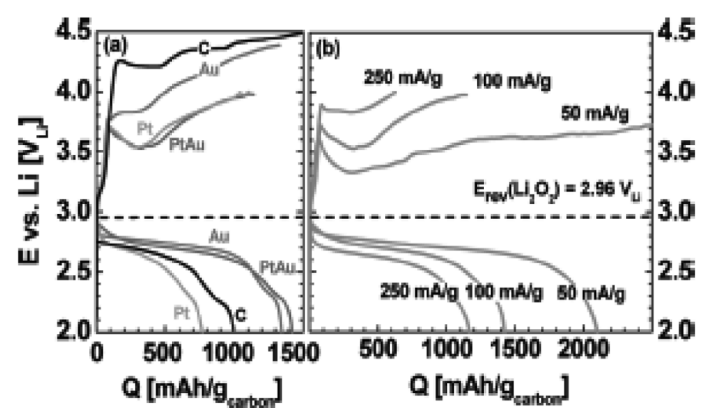

Fig. 6. (a) Li-O2 cell first discharge/charge profiles of carbon at $85 \mathrm{~mA} / \mathrm{g}$ of carbon and of $\mathrm{Au} / \mathrm{C}, \mathrm{Pt} / \mathrm{C}$, and $\mathrm{PtAu} /$ $\mathrm{C}$ at $100 \mathrm{~mA} /$ gcarbon. (b) $\mathrm{Li}-\mathrm{O} 2$ cell discharge/charge profiles (first cycle) of $\mathrm{PtAu} / \mathrm{C}$ at 50,100 , and $250 \mathrm{~mA} / \mathrm{g}$ of carbon.

$\mathrm{MnO}_{2}, \gamma-\mathrm{MnO}_{2}, \lambda-\mathrm{MnO}_{2}, \mathrm{Mn}_{2} \mathrm{O}_{3}$ and $\mathrm{Mn}_{3} \mathrm{O}_{4}$. It was observed that $\alpha-\mathrm{MnO}_{2}$ gives highest charge storage capacity ever reported around $3000 \mathrm{mAh} / \mathrm{g} . \alpha-\mathrm{MnO}_{2}$ facilitates to minimize the charging potential and other manganese based compounds support some lithium intercalation. As compared to $\alpha-\mathrm{MnO}_{2}$ the other $\mathrm{MnO}_{2}$ based catalysts exhibits lower capacities.

Although highest capacity $3000 \mathrm{mAh} / \mathrm{g}$ can be obtained up to few cycles by using $\alpha-\mathrm{MnO}_{2}$ nanowires and other catalysts, there lays a problem of capacity fading which is a point of interest. The previous results clear that the capacity fading does not lie with the type of catalyst but the voltage polarization which occurs at the end of discharge. Such type of voltage polarization can be avoided by limiting the discharge capacity to certain values that avoid such polarization. Excellent capacity retention has been obtained as in Fig. 5, ${ }^{66}$ ) where at the end of cycling only at $2400 \mathrm{mAh} / \mathrm{g}$ some capacity fading can be seen. Also by avoiding the deep discharge better cyclability can be achieved because at deep discharge large amount of discharge product $\mathrm{Li}_{2} \mathrm{O}_{2}$ are formed which results in blockage of the pores.

Lu et al. ${ }^{67)}$ has reported the investigation of different catalysts for ORR and OER. It is reported that during OER charge voltages with $\mathrm{PtAu} / \mathrm{C}$ was in the range of 3.4 to $3.8 \mathrm{~V}$ which is slightly lower than the values obtained with Pt. PtAu nanoparticles exhibit bifunctional catalytic activity having surface $\mathrm{Au}$ and $\mathrm{Pt}$ atoms responsible for ORR and OER kinetics respectively. Fig. 6(a) ${ }^{67)}$ shows the comparison of $\mathrm{PtAu} / \mathrm{C}$ with those of $\mathrm{Pt} / \mathrm{C}$ and $\mathrm{Au} / \mathrm{C}$ at same rate. The discharge voltages with $\mathrm{PtAu} / \mathrm{C}$ are comparable to those with $\mathrm{Pt} / \mathrm{C}$. The result suggests that surface $\mathrm{Pt}$ and $\mathrm{Au}$ atoms on $\mathrm{PtAu} / \mathrm{C}$ are responsible for ORR and OER kinetics respectively. Fig. $6(\mathrm{~b})^{67)}$ shows that with decreasing current density the difference between discharge and charge voltages were reduced. At $50 \mathrm{~mA} / \mathrm{g}$ of carbon with $\mathrm{PtAu} / \mathrm{C}$ catalyst the discharge capacity of $1000 \mathrm{mAh} / \mathrm{g}$ of carbon above $2.7 \mathrm{~V}$ and $1000 \mathrm{mAh} /$ $\mathrm{g}$ of carbon below $3.5 \mathrm{~V}$ are observed exhibiting a round trip efficiency of $77 \%$.

Débart et al. ${ }^{68)}$ also investigated various catalysts and their effect on the discharge performance of $\mathrm{Li}$ air battery. The group examined the use of $\mathrm{Pt}$, $\mathrm{La}_{0.8} \mathrm{Sr}_{0.2} \mathrm{MnO}_{3}, \mathrm{Fe}_{2} \mathrm{O}_{3}, \mathrm{NiO}, \mathrm{Fe}_{3} \mathrm{O}_{4}, \mathrm{Co}_{3} \mathrm{O}_{4}, \mathrm{CuO}$ and $\mathrm{CoFe}_{2} \mathrm{O}_{4}$ bulk materials $(1-5 \mu \mathrm{m})$ as catalysts. It was reported that the oxygen reduction reaction (ORR) and oxygen evolution reaction (OER) can take place even in the absence of a catalyst. Best initial capacity of $2000 \mathrm{mAh} / \mathrm{g}$ and capacity retention $(6.5 \%$ per cycle $)$ as well as the lowest charging voltage $4 \mathrm{~V}$ was reported with $\mathrm{Co}_{3} \mathrm{O}_{4}$. Among all catalyst the $\mathrm{Fe}_{2} \mathrm{O}_{3}$ delivered better performance. An electro catalyst which can promote the formation of $\mathrm{Li}_{2} \mathrm{O}_{2}$ and mean while suppressing any side reactions should be promising for lithium air battery application.

\section{Conclusions and Suggestions}

The superior energy density offered by lithium-air batteries than lithium ion batteries or other lithium batteries is due to the coupling of a lithium anode to atmospheric oxygen through a porous carbon-based air cathode. $\mathrm{Li}-\mathrm{O}_{2}$ couple is especially attractive because it has the potential of the highest specific energy $(5,200 \mathrm{Wh} / \mathrm{kg})$ among all the known electrochemical couples. Even though they possess excellent characteristics, the few important issues and challenges to be solved keeps them just closer to their practical application. Recent researches and technological developments are being carried out to reduce the limiting factors and improve the battery performances.

Future research should emphasize on the following:

- Understanding the electrochemical reaction mechanisms of Li air batteries

- Development of Li ion conducting membrane to protect Lithium from directly reacting with water

- Development of protective coating for Lithium to minimize dendrite formation

- Development of additives for electrolytes to 
increase the intercalation and not produce any decomposition products

- Development of porous Carbon cathodes which are not contaminated by discharge products or moisturized due to the atmospheric gases etc.,

- Development of a new catalyst for long cycle life, cycle efficiency and to control the redox process.

\section{Acknowledgement}

This work was supported by New \& Renewable Energy R\&D program (2009T100100606) under the Ministry of Knowledge Economy, Republic of Korea.

\section{References}

1. K. M. Abraham, and Z. Jiang, J. Electrochem. Soc.,143, 1(1996).

2. J. Read, J. Electrochem. Soc., 149, A1190 (2002).

3. J. A. Zhang, W. Xu, X. H. Li, and W. Liu, J. Electrochem. Soc., 157 , A940 (2010).

4. J. G. Zhang, D. Y. Wang, W. Xu, J. Xiao, and R. E. Williford, J. Power Sources, 195 , 433 (2010).

5. D. Vasudevan, and H. Wendt, J Electroanal. Chem. 392, 69 (1995).

6. D. L. Maricle, and W. G. Hodgson, Anal Chem 37, 1562 (1965).

7. M. E. Peover, and B. S. White, Chem Commun 183(1965).

8. C. O. Laoire, S. Mukerjee, K. M. Abraham, E. J. Plichta, and M. A. Hendrickson, J Phys Chem C 114, 9178 (2010).

9. Z. Peng, S. A. Freunberger, L. J. Hardwick, Y. Chen, V. Giordani, F. Bard, P. Novk, D. Graham, J. M. Tarascon, and P. G. Bruce, Angew Chem Int Ed 50, 6351(2011).

10. I. Kowalczk, J. Read, and M. Salomon, Pure Appl. Chem., 79(5), 851(2007).

11. B. Meyer, M. Salomon, and D. Foster. Electrospun Membranes for Li-Ion Batteries, Abstract 119, presented at the 209th meeting of the Electrochemical Society, Denver, CO, 7-12 May (2006).

12. MaxPower program on Ambient Temperature Li-Based Reserve Batteries, U.S. Army Contract No. W911QX-05C-011.

13. J. Fu, U.S. Patent 6, 485, 622, November 26, (2002) and earlier patents cited therein.

14. Alupower, Inc. Electrochemical Cathode and Materials Therefore, U.S. Patent 5,053,375, October 1, (1991.)

15. S. Hasegawa, N. Imanishi, T. Zhang, J. Xie, A. Hirano, Y. Takeda, and O. Yamamoto, J. Power Sources, 189, 371 (2009).

16. T. Zhang, N. Imanishi, S. Hasegavwa, A. Hirano, J. Xie, Y. Takeda, O. Yamamoto, and N. Sammes, J. Electrochem. Soc., 155, A965 (2008).

17. D. Zhang, R. Li, T. Huang, and A. Yu, J. Power Sources
195, 1202 (2010).

18. Y. C. Lu, H. A. Gasteiger, M. C. Parent, V. Chiloyan, Y. Shao-Horn, Electrochem.Solid-State Lett., 13, A69 (2010).

19. J. Read, J. Electrochem. Soc., 153(1), A96 (2006).

20. T. Ogasawara, A. Debart, M. Holzapfel, P. Novakand, and P. G. Bruce, J. Am. Chem. Soc., 128, 1390 (2006).

21. S. J. Visco, and Y. S. Nimon, US Patent, 7, 645, 543 (2010).

22. Y. Wang, and H. Zhou, J. Power Sources, 195, 358 (2010).

23. B. Kumar, J. Kumar, R. Leese, J. P. Fellner, S. J. Rodrigues, and K. M. Abraham, J. Electrochem. Soc., 157(1), A50 (2010).

24. S. Rajendran, and T. Uma, Mater. Lett. 44, 208 (2000).

25. S. Rajendran, P. Sivakumar, R.S. BABU Bull. Mater. Sci., 29(7), 673 (2006).

26. R. C. Agrawal, and G. P. Pandey, J. Phys. D: Appl. Phys. 41, 223001(2008).

27. G. Y. Aleshin, D. A. Semenenko, A. I. Belova, T. K. Zakharchenko, D. M. Itkis, E. A. Goodilin, and Y. D. retyakov, Solid State Ionics, 184(1), 62 (2011).

28. H. Ota, K. Shima, M. Ue, and J-ichi Yamaki Electrochimica Acta, 49, 565 (2004).

29. A. A. Arie, and J. K. Lee, Diamond \& Related Materials, 20, 403 (2011).

30. S. J. Visco, and Y. S. Nimon, U.S. Patent, 7, 282, 295 (2007).

31. M. Ishikawa, S. Machino, M. Morita, J. Electroanal. Chem., 473, 279 (1999).

32. S. Shiraishi, K. Kanamura, and Z. I. Takehara, J. Appl. Electrochem., 29, 869 (1999).

33. K. Kanamura , H. Tomura , S. Shiraishi , Z. I. Takehara, J. Electrochem. Soc., 142, 340 (1995).

34. T. Osaka, M. kitahara, Y. Uchida, T. Momma, K. Nishimura, J. Power Sources, 81-82, 734 (1999).

35. S. S. Zhang, K. Xu, and J. Read, J. Power Sources, 196, 3906 (2011).

36. N. S. Choi, Y. M. Lee, W. Seol, J. A. Lee, and J. K. Park, Solid State Ionics, 172, 19 (2004).

37. N. S. Choi, Y. M. Lee, K. Y. Cho, D. H. Ko, and J. K. Park, Electrochem. Comm., 6, 1238 (2004).

38. X. Liu, M. Zheng, and K. Xie, J. Power Sources 196, 10667 (2011).

39. S. D. Beattle, D. M. Manolescu, and S. Blair, J. Electrochem. Soc. 156(1), A44 (2009).

40. M. Wang, Y. Yang, and Y. Zhang, Nanoscale, 3, 4434 (2011).

41. S. Yang, X. Wang, X. Yang, Z. Liu, Q. Wei, and H. Shu, International Journal of Electrochemistry, 2012, Article ID 323560, 9 (2012).

42. Z. Chen, D. J. Lee, Y. K. Sun, and K. Amine, MRS Bulletin, 36, 498 (2011).

43. P. Kichambare, J. Kumar, S. Rodrigues, and B. Kumar, J. Power Sources, 196, 3310 (2011).

44. X. H. Yang, P. He, and Y. Y. Xia, Electrochem. Comm., 11, 1127 (2009). 
45. J. Xiao, D. Wang, W. Xu, D. Wang, R. E. Williford, J. Liu, and J.G.Zhang, J.Electrochem. Soc., 157 (4), A487 (2010).

46. G. Q. Zhang, J. P. Zheng, R. Liang, C. Zhang, B. Wang, M. Hendrickson, and E. J. Plichtae, J. Electrochem. Soc., 157(8), A953 (2010).

47. J. Read, K. Mutolo, M. Ervin, W. Behl, J. Wolfenstine, A. Driedger, and D. Foster, J. Electrochem. Soc. 150, A1351 (2003)

48. X. H Yang and Y. Y Xia, Solid State Electrochem., 14, 109 (2010).

49. C. Tran, X. Q Yang, and D. Qu, J. Power Sources, 195 $2057(2010)$.

50. W. Xu, J. Xiao, D. Wang, J. Zhang and J. G. Zhang, J. Electrochem. Soc., 157(2), A219 (2010).

51. S. S. Zhang, Journal of Power Sources, 196, 2867 (2011).

52. W. Xu, V. V. Viswanathan, D. Wang, S. A. Towne, J. Xiao, Z. Nie, D. Hu, and J. G. Zhang, J. Power Sources, 196, 3894 (2011).

53. J. Xiao, J. Hu, D. Wang, D. Hu, W.Xu, G. L. Graff, Z. Nie, J. Liu, and J. G. Zhang, J. Power Sources, 196, 5674 (2011).

54. T. Kuboki, T. Okuyama, T. Ohsaki, and N. Takami, J.Power Sources, 146, 766 (2005).

55. P. Kichambare, J. Kumar, S. Rodrigues, and B. Kumar, J. Power Sources, 196(6), 3310 (2011).
56. J. W. Fergus, J. Power Sources, 195, 4554 (2010).

57. D. Zhang, R. Li, T. Huang, and A.Yu, J. Power Sources, 195, 1202 (2010).

58. H. P. Zhang, P. Zhang, G. C. Li, Y. P. Wu, and D. L. Sun, J. Power Sources, 189(1), 594 (2009).

59. P. Bonhote, P. Dias, N. Papageorgiou, K. Kalyanasundaram, and M. Gratzel, Inorg. Chem., 35, 1168(1996).

60. X. Ren, S. S. Zhang, D. T. Tran, and J. Read, J. Mater. Chem., 21, 10118 (2011).

61. A. Débart, A. J. Paterson, J. Bao, and P. G. Bruce, Angew Chem Int Ed Engl., 47(24) 4521 (2008).

62. Y. Shao, S. Park, J. Xiao, J. G. Zhang, Y. Wang, and J. Liu, ACS Catal., 2, 844 (2012).

63. A. K.Thapa, K. Saimen, and T. Ishihara, Electrochem. Solid-State Letters, 13 (11) A165 (2010).

64. A. K. Thapa and T. Ishihara, J.Power Sources, 1967016 (2011).

65. G. Q. Zhang, J. P. Zheng, R. Liang, C. Zhang, B. Wang, M. Au, M. Hendrickson, and E. J. Plichta, J. Electrochem Soc., 158 (7), A822 (2011)

66. A. Débart, A. J. Paterson, J. Bao, and P. G. Bruce, Angew. Chem., 120, 4597 (2008).

67. Y. C. Lu, Z. Xu, H. A. Gasteiger, S. Chen, K. H. Schifferli, and Y.S.Horn, J. AM. CHEM. SOC., 132, 12170 (2010).

68. A. Débart, J. Bao, G. Armstrong, and P. G. Bruce, J. Power Sources, 174, 1177 (2007). 